\title{
INTERFACES
}

Sociologias, Porto Alegre, ano 4, № 7, jan/jun 2002, p. 254-270

\section{Na trilha do Jeca: M onteiro Lobato, o público leitor e a formação do campo literário no Brasil ${ }^{*}$}

EIIO PASSIAN**

\section{Um solo fértil de idéias}

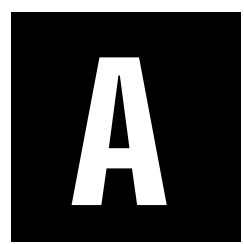

Primeira República trouxe ao Brasil, no seu alvorecer, uma lufada de esperança: a liberdade definitiva em relação à família real e a possibilidade de alargar a participação política aos outros setores da sociedade, o incremento dos negócios em virtude do comércio do café, a penetração de capital estrangeiro, uma incipiente industrialização, etc. Respirava-se os ares da modernidade e da modernização e a Belle Époque atracava em terras brasileiras - a rigor, apenas nas grandes cidades próximas da faixa litorânea, como São Paulo e notadamente o Rio de Janeiro, capital da Belle Époque nacional.

A imagem do progresso - versão prática do conceito homólogo de civilização - se transforma na obsessão coletiva da nova burguesia. (Sevcenko, 1995, p.29). Tal obsessão se reflete na paisagem urbana: no Rio de Janeiro, por exemplo, erguem-se monumentos celebrando os novos tempos, são demolidos os casarões coloniais e imperiais do centro da cidade, e as avenidas são ampliadas. O s hábitos e costumes ligados à chamada sociedade tradicional são igualmente condenados. Nada escapa ao processo de "regeneração" da cidade, contaminada pelo ar da (suposta) redenção completa da situação colonial ${ }^{1}$.

* U ma versão bastante resumida deste artigo foi apresentada sob a forma de comunicação oral no IX Congresso Brasileiro de Sociologia, realizado em Porto Alegre, entre 30 de agosto e 3 de setembro de 1999.

** Mestre em Sociologia e Professor na Universidade de São Paulo (USP).

1 Para uma discussão mais aprofundada do tema, consultar SEVCENKO, Nicolau. Literatura como missão. São Paulo: Brasiliense, 1995; e os volumes 8 e 9 da excelente (e bastante útil) coleção História geral da civilização brasileira, ambos organizados pelo Prof. Boris Fausto. 
Contudo, nossa Belle Époque possuía uma face mais sombria. A redenção era válida apenas (e ainda assim parcialmente) para as grandes cidades. 0 sertão brasileiro conhecia somente a miséria, as doenças e 0 descaso do Estado. A abolição e a crise cafeeira, por sua vez, arrastaram imensas massas humanas para as cidades:

(...) a oferta de mão-de-obra abundante excedia largamente a demanda do mercado, aviltando os salários e operando com uma elevada taxa de desemprego crônico. Carência de moradias e alojamentos, falta de condições sanitárias, moléstias (alto índice de mortalidade), carestia fome, baixos salários, desemprego, miséria: eis os frutos mais acres desse crescimento fabuloso e que cabia à parte maior e mais humilde da população provar (Sevcenko, 1995, p.52).

Num ambiente que oscilava entre a euforia desmedida de alguns setores da sociedade e um painel social mais grave, os intelectuais brasileiros adotavam duas posturas assimétricas. De um lado, aqueles que pregavam o progresso, a abolição, a república e a democracia como a panacéia do país e, para tanto, acreditavam que a saída era atualizar a sociedade brasileira com o modo de vida típico europeu (daí a importação de modelos artísticos e culturais, principalmente franceses)2. De outro lado, havia aqueles intelectuais que, influenciados pelo cientificismo - também importado da Europa -, adotavam uma postura diferenciada e preconizavam o mergulho na realidade brasileira para melhor conhecê-la, o estudo aprofundado de nossa história, nossos processos, características e problemas. Estes últimos estavam preocupados em construir um saber próprio sobre o Brasil e, quiçá, transformar a realidade.

É no bojo de tais reflexões que nascem inúmeras teorias e projetos sobre o país e sua população, desde os mais ufanistas até aqueles mais

2 Este contexto de radical otimismo, marcado pela imitação de costumese da arte européias, exerce influência sobre parte de nossa produção literária: exageradamente erudita, elitista e até descomprometida em relação às questões sociais, tal literatura ficou conhecida como "sorriso da sociedade", típica da boêmia literária, dos dandys que dominavam os cafés, restaurantese salões literários. Para maiores detalhes sobre o período, consultar o ótimo trabalho de MACH ADO NETO , A. L. A estrutura social da República das Letras. São Paulo: EDUSP/Grijalbo, 1973. 
descontentes, descrentes e mais críticos. Interessam-me, particularmente, os escritores engajados, os literatos preocupados com as grandes questões nacionais da época. Nas palavras de Antônio Cândido: Diferentemente do que sucede em outros países, a literatura tem sido aqui, mais do que a filosofia e as ciências humanas, o fenômeno central da vida do espírito (Cândido, 1976, p.156). E são justamente esses escritores militantes que produzem as obras mais representativas do período, que ocupam efetivamente o centro da vida espiritual do país 3 .

E, dentro da história literária brasileira, o período conhecido como prémodernista ${ }^{4}$ ofereceu expressões interessantes do pensamento nacional. Ao contrário do que por muito tempo se apregoou, esta não é uma fase de "estagnação da atividade literária", tampouco de empobrecimento e/ou esterilidade da produção literária (M iceli, 1977, p.13-15). Euclides da Cunha e Lima Barreto, como aponta Sevcenko, a despeito de suas diferenças, empenharam-se no debate, na análise e no combate de questões que ambos julgavam essenciais para o entendimento e a transformação do momento histórico que viviam.

Euclides da Cunha, preocupado com as turbulências republicanas (...) delineia todo um programa de ação capaz de restaurar a moralidade, a dignidade e a racionalidade no país, entregando-o de volta ao seu destino natural (Sevcenko, 1995, p.148). Euclides propõe um conjunto de reformas para recolocar o Brasil nos trilhos de seu desenvolvimento, todas elas balizadas pelo saber científico, tão valorizado pelo escritor.

Assim como Euclides, Lima Barreto também acreditava na inserção social do escritor, no seu dever quase cívico de interferir na realidade.

No projeto de Lima Barreto a necessidade de uma literatura posta em situação conduz à estratégia de recuperar uma espécie de autonomia da verdade literária, o que torna de certo modo implícita a obsessão em perseguir

$3 \mathrm{~N}$ as três primeiras décadas deste século há uma convivência e um diálogo intensos, no Brasil, entre literatura e ciências sociais. Mas, a meu ver, esse profícuo diálogo não se dá com qualquer tipo de literatura, mas com aquela que podemos chamar de engajada ou militante.

4 Para uma avaliação crítica do próprio termo pré-modernismo, com toda carga ideológica que carrega, consultar LEITE, Sylvia Helena Telarolli de Almeida. 0 pré-modernismo em São Paulo. In: Revista de Letras. São Paulo: UNESP, v. 35, 1995. 
em cada texto um fundo revolucionário latente que 0 amoldasse às contradições presentes nos temas que 0 inspiravam (Prado, 1989, p.25).

Enquanto no projeto euclideano a literatura se transforma em veículo de suas idéias de reforma social, em Lima Barreto a própria literatura, a própria linguagem, é objeto de reflexão e mudança. $\mathrm{O}$ u seja, sua literatura militante, além do escopo sociológico e do projeto de reformulação social, trazia embutida uma pesquisa estética (filiada ao plano social e político).

A literatura pré-modernista, em certo sentido, modificou e aproximou as relações entre escritor e público ao se tornar porta-voz desse público, dos seus anseios, desejos e necessidades. A aproximação também reverbera nos procedimentos estilísticos: filiação com a oralidade, incorporação de temas folclóricos, mergulho no regionalismo. As transformações formais são acompanhadas de mudanças no conteúdo das obras, cada vez mais voltadas para temas populares e cotidianos e que retratavam, em certa medida, a condição e o imaginário do público leitor.

O utro autor que elabora um projeto dentro desses moldes - e menos conhecido que os dois anteriormente citados - é o gaúcho João Simões Lopes Neto. 0 projeto de Simões Lopes, de acordo com Lígia Chiappini Moraes Leite, possuía intenções explícitas, isto é, contornos ideológicos bem definidos que marcam a opção do escritor pelos excluídos da República e uma desconfiança em relação aos dogmas do progresso (Leite, 1988, p.147) e intenções implícitas, que dizem respeito à poética de Simões Lopes, como a incorporação de mitose lendas do sul em sua obra e o emprego de uma linguagem próxima à oralidade.

É nesse solo fértil de idéias sobre e para o Brasil que é possível enquadrar Monteiro Lobato. 0 escritor vale-paraíbano, assim como outros tantos intelectuais do período, também tinha um projeto para o país, também fez de sua pena sua principal arma de combate contra as mazelas da jovem república. Mas a intenção deste artigo é mostrar a peculiaridade e a originalidade do projeto lobatiano, aquilo que o distinguia dos demais componentes de nossa intelligentsia. Então, o que era o projeto de Lobato? Em que consistia? 


\section{O Projeto lobatiano: a pena e o escritor}

Um primeiro ponto que chama a atenção em Monteiro Lobato e que o distingue de outros escritores do mesmo período é o fato de que ele concebeu um projeto eminentemente literário, pois, ao contrário de outros literatos contemporâneos do escritor paulista, a literatura não constituía mero veículo das transformações ou simples porta-voz das idéias de mudança, mas o próprio instrumento das transformações ${ }^{5}$. A novidade do projeto literário de Lobato é seu desdobramento em duas frentes igualmente importantes: a própria escrita literária e o empreendimento editorial. Aqui me ocuparei do texto lobatiano.

Em carta endereçada ao seu amigo Godofredo Rangel em 1908 portanto, bem antes de se tornar um autor consagrado -, Lobato já indica qual o material que mais tarde utilizará em seus contos: $0 \mathrm{~s}$ artistas subjetivos que só tiram de si em vez de tirar do mundo que os rodeia, ficam introspectivos em excesso e acabam satisfazendo a um público muito restrito: a si mesmos ${ }^{6}$.

Lobato, pois, era um escritor que valorizava a observação cuidadosa do ambiente que o circundava - fruto da influência das teorias cientificistas do início do século - para justamente cumprir aquele que julgava ser 0 papel social do intelectual: produzir conhecimento e torná-lo acessível a um público sempre maior. 0 público aparece como potencialidade do texto lobatiano e não como mero receptor passivo da informação.

A literatura militante de Lobato procurava conquistar um público cada vez mais amplo, apontar para seus leitores os problemas do país e convidálos para a ação. M onteiro Lobato é, acima de tudo, arguto crítico social, um homem preocupado com os destinos do seu país (Azevedo, 1997, p.58). E é fácil notarmos tal característica ao longo de toda sua obra. Já no seu primeiro livro de contos, Urupês, Lobato incorpora dois artigos que publicara n' 0 Estado de S. Paulo: Velha Praga e U rupês. Neles, o escritor paulista denuncia

5 Nicolau Sevcenko, ao analisar a obra de Euclides da Cunha e Lima Barreto, afirma que, nesses autores, as transformações não se dão na literatura, mas por meio dela.

6 Ver LOBATO, Monteiro. A barca de Gleyre. São Paulo: Brasiliense, tomo 1, 1951, p.221. 
as queimadas comuns nas regiões interioranas do Estado e cria um dos seus principais personagens, o Jeca Tatu, avesso da imagem romântica do caboclo, para revelar, segundo ele, a "verdadeira" face do homem do campo: indolente e doente. Em Cidades mortas, Lobato nos oferece a triste realidade do Vale do Paraíba, outrora uma região rica devido ao cultivo do café, e transformada num terreno de miséria e fantasmas. 0 livro 0 problema vital alerta quanto ao problema do saneamento do país e é inteiramente dedicado à campanha da vacinação. A lista poderia continuar e seria extensa. 0 que é preciso frisar é o engajamento do escritor em praticamente todas as questões sociais do país: queimadas, saneamento, petróleo, eleições, etc. problemas que faziam parte do cotidiano do povo brasileiro, sempre questões da ordem do dia. E foi este o material sobre o qual M onteiro Lobato se debruçou para elaborar o enredo de seus livros.

Q uanto aos aspectos formais da escrita lobatiana, utilizo novamente um pequeno trecho de uma carta endereçada ao seu epistolar amigo, Godofredo Rangel: Na propriedade da expressão está a maior beleza; dizer 'chuva' quando chove - 'sol' quando soleja. É a porca que entra exata na rosca do parafuso (Carta de 04/01/1904) 7 .

A linguagem exata, o texto enxuto, na medida certa, sem ornamentos e excessos, que atingisse diretamente 0 leitor, que o incorporasse ao próprio texto. Sua maneira clara e direta de escrever, portanto, visava a um único objetivo, a saber, ampliar o número de leitores. E, para tanto, preconizava uma estética de fácil apreensão, o cultivo de um estilo que refletisse uma oralidade tipicamente nacional, livre de imitações e da erudição basbaque ${ }^{8}$.

Em vários artigos reunidos no volume Idéias de Jeca Tatu, encontramos a proposta estética de Lobato: ele defendia a criação de um estilo propriamente brasileiro, livre das influências estrangeiras, da simples cópia

7 Idem, p.46.

8 Daí a predileção de Lobato pelos contos, que, segundo ele, possuíam a medida exata, pois prendiam a atenção do leitor, envolviam-no, levavam-no à reflexão e não o cansavam. 
de modelos e que negasse os excessos ornamentais do art nouveau'; um estilo que remetesse às nossas origens e que reconhecesse nossa mestiçagem (Lobato, 1948, p.35). 0 estilo, segundo o escritor, é espelho dos costumes, dos usos, das necessidades, de nossa intimidade racial (Lobato, 1948, p.92).

Todo o programa estético de M onteiro Lobato já era visível em U rupês, publicado em 1918. Vasda Bonafini Landers assinala que esse livro (...) é o primeiro documento da nossa modernidade literária: aí a língua já é brasileira, de sabor inteiramente nacional e o herói (...) é caracteristicamente 0 homem da terra (Landers, 1988, p.26). A literatura lobatiana valorizava os traços orais da linguagem, incorporando um sem número de expressões regionais, os coloquialismos e brasileirismos típicos da fala popular - além dos neologismos freqüentemente utilizados pelo escritor ${ }^{10}{ }_{-}$, negava veementemente 0 rebuscamento exagerado, rompendo com a rigidez gramatical ${ }^{11} \mathrm{e}$ a fixidez da linguagem, e combatia a literatice que afastava os leitores dos livros. E é aqui que encontramos a contribuição lobatiana: pela primeira vez, o público passava a ser parte integrante da obra literária. Para Lobato, a separação entre a língua falada e a escrita constituía o fundamental problema da separação entre escritor e leitor e, por conseguinte, da ausência de um público ledor mais amplo. Foi ele, pode-se dizer, o primeiro a se preocupar em fazer dessa massa isolada, parte do processo da produção literária, elevando-a a leitor-participante (Landers, 1988, p.76).

0 público, de acordo com M onteiro Lobato, era o tribunal dos escritores e decidia qual o futuro dos livros: ou o êxito ou o malogro. Lobato queria ser lido pelo grande público e, por essa razão, tanto em relação ao conteúdo quanto à forma, tentava aproximar o máximo possível seus textos dos leitores: abordava os temas que lhes interessavam e se utilizava de certos recursos estilísticos que permitiam uma fácil apreensão por parte do

9 Para uma lúcida discussão acerca do art nouveau, consultar PAES, José Paulo. 0 art nouveau na literatura brasileira. In: PAES, José Paulo. Gregos e baianos. São Paulo: Brasiliense, 1985.

10 Entre os neologismos podemos citar: olhodarruável, etcetrano, luademelou, olhômetro, morremorrendo. E dentre os regionalismos é possível lembrarmos de uruca, judiação, lambança, badulaque, amode que, quedele, vassuncê, lesmice.

110 conto 0 colocador de pronomes, presente no livro Negrinha, ilustra muito bem o desinteresse e o desapego de Lobato quanto ao rigor gramatical. 
público. Mas a preocupação com os leitores não permitia a Lobato abrir mão de seus princípios: sua literatura era eminentemente militante, crítica e social, voltada para os problemas que assolavam a nação, e a linguagem literária, por sua vez, ainda que destinada ao grande público, era elegante e apurada, cuidadosamente construída - Lobato revisava inúmeras vezes os seus escritos. Era sua prática publicar os textos nos periódicos para depois corrigi-los, reescrevê-los e editá-los ${ }^{12}$.

\section{O projeto lobatiano: a revolução editorial}

A outra face do projeto de M onteio Lobato, ligada à anterior por uma mesma concepção de literatura, é a sua atividade no ramo editorial. Para termos uma noção mais clara da importância de Monteiro Lobato para 0 desenvolvimento do setor editorial brasileiro, creio ser necessário traçar o perfil deste mercado no período um pouco anterior à ação lobatiana.

Em meados do século XIX, livreiros importadores e editores fixaramse na corte, sendo uma boa parte deles filiais de grandes casas editoriais européias.

Trabalhavam distribuindo a produção literária estrangeira e também editavam alguns autores brasileiros da época (...) - Laemmert, Garnier e Francisco Alves foram os principais livreiros importadores e editores da segunda metade do século XIX no Brasil (Koshiyama, 1982, p.23).

Nesse período, as tiragens eram reduzidas e vendiam-se poucos livros. De acordo com Koshiyama, as cifras de vendas de livros indicavam as restritas possibilidades de consumo do livro no Brasil, no último quartel do século XIX. E no século XX, aponta Hallewell, a situação continuava desalentadora: os pontos de venda eram restritos e a produção editorial estava circunscrita aos livros didáticos e livros sobre a legislação brasileira (Hallewell, 1985, p.235).

12 Sobre o processo de reescrita dos textos de M onteiro Lobato, ver M ARTINS, Milena Ribeiro. E era à máquina e de pijamas que Lobato escrevia. In: LO PES, Eliane M arta Teixeira \& GO UVÊA, M aria Cristina Soares de. Lendo e escrevendo Lobato. Belo Horizonte: Autêntica, 1999. 
Ciente desta situação, Lobato escreve a Rangel, em 1915: Não há livros, Rangel, afora os franceses. Nós precisamos entupir este país com uma chuva de livros ${ }^{13}$. E ao adquirir a Revista do Brasil junto ao Estado de $\mathrm{S}$. Paulo, em 1918, Lobato inicia imediatamente a revolução editorial. 0 primeiro passo foi utilizar a própria revista como veículo de propaganda para os livros que editava, para, em seguida, começar a anunciar noutros periódicos. 0 segundo passo foi melhorar as condições de distribuição do livro:

Para aumentar a rede de distribuidores, ele enviou cartas a cerca de 1200 endereços de comerciantes propondo que aceitassem livros em consignação. Se os livros fossem vendidos, os comerciantes teriam $30 \%$ de comissão sobre 0 preço do produto vendido; se não, dentro de um prazo determinado, poderiam devolver a mercadoria, sendo 0 frete pago pelo editor (Koshiyama, 1982, p.72-73).

A Revista do Brasil, que já gozava de algum prestígio antes de Lobato adquiri-la, sob sua direção torna-se o periódico mais importante e influente do meio intelectual e literário da década, uma vez que reunia, entre seus colaboradores, intelectuais com algum peso, que utilizavam a própria Revista como porta-voz de seus ideais ${ }^{14}$.

O sucesso da revista permitiu a Lobato, em meados de 1920, junto com Marcondes $O$ ctalles Ferreira, fundar a Monteiro Lobato \& Cia. E, mais uma vez, Monteiro Lobato sacode o mercado editorial. Disposto a transformar o livro numa mercadoria atraente, que chamasse a atenção dos potenciais consumidores, ele é responsável por uma inovação sem precedentes dos seus aspectos gráficos. Por volta de 1920, a capa típica dos livros era apenas a reprodução, principalmente em papel amarelo - às vezes também era utilizado o papel cinza -, dos caracteres tipográficos que

13 Ver LOBATO, A barca de Gleyre, 20 tomo, p.7.

14 Landers chega a afirmar que: A Revista passa a ser imediatamente um centro intensivo de debates sobre assuntos brasileiros de toda ordem; da política à literatura. Ali se concentraram os mais importantes nomes do momento e o espírito era essencialmente brasileiro, principalmente depois de 1918 quando M onteiro Lobato compra a revista e assume a sua direção(Landers, 1988, p.100). 
apareciam na página de rosto (Hallewell, 1985, p.251). Lobato passou a utilizar ilustrações nas capas dos livros de sua editora, realizadas por conhecidos pintores brasileiros da época, como Di Cavalcanti, Anita Malfatti e J. Prado. 0 aspecto interno foi igualmente melhorado: diagramação, tipo de letra, ilustrações, qualidade do papel; tudo era feito para conquistar novos leitores.

Lobato também inovou quanto aos escritores por ele editados. Privilegiava os novos talentos, os que ainda não estavam consagrados e foi responsável pelo lançamento de Oliveira Vianna, Lima Barreto, Menotti del Picchia, Oswald de Andrade e tantos outros ${ }^{15}$. 0 Lobato-editor criou um circuito que ultrapassava os limites da impressão das obras e produzia (...) as condições sociais que tornam possível a redação, publicação e 0 consumo do livro, dentre as quais se destacam a divulgação e a circulação deste bem cultural (Moraes, 1996, p.234-235).

Lobato, num certo sentido, dessacralizou o livro, desfez a aura que 0 cercava e que o definia como um artigo de luxo, cujo usufruto era restrito a uma pequeníssima parcela da população, alguns poucos "eleitos" que tinham acesso àquele totem chamado livro. Lobato encarava o livro como uma mercadoria - de primeira necessidade, é certo. E por isso deveria estar na mesa e ser consumido pelo maior número possível de brasileiros. Inserir o livro nos moldes da produção e circulação de mercadorias típicas do sistema capitalista criava, segundo ele, as condições necessárias para se estabelecer a relação entre obra e público, logo, para a circulação do texto literário e o consumo do livro.

Neste ponto, vislumbramos a peculiaridade e a originalidade do projeto literário lobatiano: as duas linhas de ação que emanam do projeto são unidas por uma mesma preocupação, a saber, a aproximação entre público e obra, a criação de canais que possibilitem o encontro entre

15 Cabe frisar que vários escritores escolhidose editados por Lobato eram donos de estilose temáticas inéditas até então, cujas obras discutiam alguns dos problemas nacionais. É importante lembrar que esta preocupação - debruçar-se sobre as questões nacionais - era uma marca característica da atuação de M onteiro Lobato, seja na sua vertente propriamente literária, seja na sua atuação como editor. 
escritores e leitores ou, noutros termos, a ampliação incessante do mercado consumidor de livros. 0 escritor e o editor M onteiro Lobato são um único agente social que pôs em prática uma concepção moderna de literatura, que incluía o leitor como virtualidade presente no texto (Lajolo, 1983, p.43). Notamos, pois, que a atuação literária e editorial de Lobato foi movida por uma única concepção de literatura: o bem cultural "literatura" não é anterior e nem deve sobrepujar o leitor; ao contrário, ela só ganha sentido na medida em que é aceita e consumida pelo público. E a literatura somente é aceita e consumida quando responde às necessidades e desejos do público leitor e quando se coloca no mesmo nível de linguagem desse público. Daí o caráter social e militante da literatura lobatiana, bem como a incorporação da coloquialidade na sua linguagem literária. Para (e em) M onteiro Lobato, a literatura só existe se há um público - a recepção do texto constituía a preocupação basilar da atuação editorial e da escrita lobatianas.

Seria um erro imaginar que por trás de tal preocupação havia uma concepção unívoca de literatura e de público. Monteiro Lobato sabia que não havia apenas um público, mas vários, e, por conseguinte, muitas formas de manifestação literária ${ }^{16}$. E o que atesta tal percepção é o fato de que, como editor, Lobato publicou livros didáticos, ensaios sociológicos, romance, poesia, contos, novelas e, como escritor, dedicou-se aos contos, à literatura infantil, à crítica literária e de arte, à crônica, ao ensaio e até ao panfleto de cunho político ${ }^{17}$. 0 que é possível dizer, quando se trata do projeto literário de Lobato, é que seu objetivo primordial era atingir aquela massa de não-leitores, aqueles que estavam distantes dos livros, ou seja, sua meta era a formação e ampliação de um público leitor ainda inexistente no Brasil.

16 É o que Bourdieu chama de categorias de público e categorias de obras.

170 pequeno livro Zé Brasil, escrito por Lobato em 1947, trazia em seu enredo a defesa dos pequenos agricultores e 0 ataque aos grileiros, denunciando a estrutura agrária brasileira. 0 teor político (mas não partidário) e crítico do livro desagradou as autoridades estatais e foi considerado perigoso à segurança nacional, o que implicou a apreensão e censura do livro. Para maiores detalhes, ver CARN EIRO, M aria Luiza Tucci. Livros proibidos, idéias malditas - o Deopse as minorias silenciadas. São Paulo: Estação Liberdade, 1997. 


\section{Conclusão: Lobato e a formação do campo literário no Brasil}

Segundo Robert Darnton, os livros possuem, aproximadamente, o mesmo ciclo de vida:

Este pode ser descrito como um circuito de comunicação que vai do autor ao editor (se não é o livreiro que assume esse papel), ao impressor, ao distribuidor, ao vendedor, e chega ao leitor. 0 leitor encerra o circuito porque ele influencia 0 autor tanto antes quanto depois do ato de composição. O s próprios autores são leitores. Lendo e se associando a outros leitores e escritores, eles formam noções de gênero e estilo, além de uma idéia geral do empreendimento literário, que afetam seus textos, quer estejam escrevendo sonetos shakespearianos ou instruções para montar um kit de rádio. U m escritor, em seu texto, pode responder a críticas a seu trabalho anterior ou antecipar reações que serão provocadas por esse texto. Ele se dirige a leitores implícitose ouve a resposta de resenhistas explícitos. Assim o circuito percorre um ciclo completo. Ele transmite mensagens, transformando-as durante o percurso, conforme passam do pensamento para o texto, para a letra impressa e de novo para 0 pensamento (Darnton, 1995, p.112).

A longa citação de Robert Darnton serve para ilustrar a importância e o papel do leitor na produção literária - que, como vimos, envolve escritores e editores, além de outros agentes sociais -, o grau de interferência e envolvimento do público ledor nos textos literários. Se o leitor ocupa posição central no processo de produção da literatura, não é descabida a indagação sociológica sobre quem lê o quê, em que condições, em que momento e com que resultados (Darnton, 1995, p.129), pois só assim será possível compreender a formação de um campo literário.

Num artigo publicado em 1993, Wendy Griswold assinala que a mais significativa mudança de direção nas pesquisas sociológicas acerca da literatura na última década é justamente a reconceituação dos leitores como agen- 
tes criativos, abandonado a noção de leitor como recipiente passivo daquilo que os escritores escrevem. Assim como Darnton, Griswold também afirma que os padrões de leitura constituem objeto da investigação sociológica.

Mas, enfim, qual o papel do leitor no processo de estruturação do campo literário?

O sistema de produção de bens simbólicos e da própria estrutura de tais bens, está intimamente associada à constituição progressiva de um campo intelectual e artístico, (...) ou seja, à autonomização progressiva do sistema de relações de produção, circulação e consumo de bens simbólicos (Bourdieu, 1998, p.99). A autonomia do campo intelectual e artístico se dá em relação aos campos econômico, político e religioso, noutras palavras, em relação a todas aquelas instâncias que pretendem legislar na esfera cultural em nome de um poder e/ou uma autoridade que não é propriamente cultural. De acordo com Pierre Bourdieu, o processo de autonomização do campo artístico ${ }^{18}$ liga-se a uma série de outras transformações: a constituição de um público de consumidores cada vez mais amplo e socialmente diversificado, a constituição de um corpo igualmente numeroso e diferenciado de produtores e empresários de bens simbólicos e, por fim, a multiplicação das instâncias de consagração.

O ra, fica evidente que a independência do campo literário em relação às influências e ingerências de outros campos depende da liberdade dos produtores culturais (sejam os escritores ou os editores) frente aos mecenas, às autoridades estatais e eclesiásticas. E tal liberdade, por sua vez, só é conquistada se os produtores de bens simbólicos possuírem seu próprio público consumidor, que fornecerá os ganhos materiais e simbólicos necessários para manter a existência desses produtores, bem como direcionará a produção de bens culturais para esta ou aquela direção, independentemente das diretrizes instaladas noutros campos. 0 s produtores culturais não estarão mais sob as leis que regem os outros campos, mas sob aquelas regras elaboradas dentro do próprio campo literário e pelos agentes sociais que dele fazem parte (leitores, escritores, editores, etc. ${ }^{19}$. Em resumo: a formação e a extensão do público leitor é condição sine qua non para a autonomização do campo literário.

18 De agora em diante utilizarei o termo "campo literário", que é o objeto de discussão deste artigo, além de não fugir à terminologia do próprio Bourdieu.

19 É claro que o campo literário não se debruçará sobre si mesmo e se tornará imune aos fatos políticos e econômicos, por exemplo. O s campos se comunicam entre si e se influenciam mutuamente. A autonomia de um determinado campo implica a mediação de tais influências, que não se darão mais de forma direta, pelas regras e agentes do próprio campo. 
Nesse sentido, a ação de Lobato é parte fundamental do processo de formação de um campo literário no Brasil. Sua intensa e infatigável batalha para a formação do público leitor, que, como vimos, pode ser percebida na sua atividade propriamente literária e editorial, possibilitou um princípio de autonomia para o campo ${ }^{20}$. Seu projeto literário foi responsável pela criação de um novo habitus literário, que tomava o leitor como potencialidade, como parte integrante da produção cultural. 0 público - a partir de Lobato -, com toda sua heterogeneidade e pluralidade, passou a constituir 0 alvo de escritores e editores ${ }^{21}$.

Ao mergulhar no texto lobatiano é imediatamente perceptível seu cuidado com o leitor, sua intenção de conquistá-lo - seja por intermédio da forma, seja por meio do conteúdo. A ação editorial de Lobato, num segundo momento (mas não menos importante), somente comprova a atenção que dedicava ao público, uma vez que as estratégias revolucionárias que adotou - a melhoria na distribuição do livro, a propaganda, a renovação gráfica, a escolha dos escritores a serem editados - visavam levar o livro ao maior número possível de leitores.

No afã de criar um mercado consumidor de literatura, Lobato não se entregou à subordinação total às demandas externas ao campo literário, tampouco se manteve absolutamente independente em relação ao mercado e às suas exigências. Se, por um lado, adotou práticas avalizadoras do lucro como direito do empresário editor e gráfico (Koshiyama, 1982, p.188), por outro, sempre buscou editar escritores que, segundo ele, apresentassem qualidades literárias, que possuíssem talento ${ }^{22}$ - a noção de talento

20 Cabe, aqui, doisalertas: primeiro, não é minha intenção estabelecer a atuação de M onteiro Lobato (seja a propriamente literária, seja a editorial) como uma espécie de marco zero na história cultural brasileira, como o criador de um campo literário nacional, pois, efetivamente, ele não o foi - o processo de estruturação do campo literário encontrava-se em gestação já há algum tempo, configurando certas condições sócio-históricas apropriadas para a ação de um ator social individualizado, no caso, M onteiro Lobato. Em segundo lugar, não cabem neste artigo consideracõos acerca dastensõese conflitos que perpassam o campo literário e nos quais Lobato esteve envolvido (como por exemplo asrusgas de Lobato com o grupo dosintelectuaismodernistas principalmente Mário deAndrade), uma vez que não é este o meu objetivo, mas sim chamar a atenção e discutir o papel sui generisde M onteiro Lobato na construção de um campo literário no Brasil. As disputasentre Lobato e outrosagentes sociaisno interior do campo literário brasileiro fornecem material suficiente para outro artigo a ser desenvolvido alhures.

21 Para uma avaliação mais detida do impacto das estratégias editoriais de Lobato sobre os futuros editores, ver PO NTES, Heloísa. Retratos do Brasil: editores, editoras e 'Coleções Brasiliana' nas décadas de 30, 40 e 50. In: MICELI, Sérgio. História das ciências sociais no Brasil - volume 1. São Paulo: Vértice/IDESP, 1989.

22 Para confirmar esta afirmação, basta consultar o catálogo de sua editora, a Monteiro Lobato \& Cia. Alguns dos escritores lançados por Lobato foram: os modernistas 0 swald de Andrade e Menotti del Picchia, Godofredo Rangel, Valdomiro Silveira, Hilário Tácito, entre outros. 
não era apenas uma invenção individual, de Lobato, por exemplo, mas era estabelecida de acordo com as regras e critérios elaborados especificamente pelos agentes e agências sociais que compunham o campo literário.

$E$, vale lembrar, Monteiro Lobato em nenhum momento abriu mão de sua literatura militante, crítica (às vezes cáustica demais), de cunho visivelmente social, em nome dos consumidores; não abandonou a crença no poder transformador da literatura: os livros deveriam ser um convite para a reflexão e para a ação.

Uma literatura engajada, que tratasse dos problemas da nação, que se voltasse para as questões que afetavam boa parte da população no seu dia-a-dia, que sugerisse alternativas para o país e que buscasse a melhoria das condições de vida do povo. Eis a maneira que Lobato enxergava para aproximar os livros do público e aumentar constantemente o número de leitores. E tal concepção não era meramente instrumental uma vez que 0 próprio público (num primeiro instante, virtual) fornecia matéria para a literatura, que a devolveria de forma transformada, trabalhada literariamente. A investigação sociológica permite afirmar que a literatura, em Lobato, é social porque é produto de condições sociais específicas e metassocial porque, como um produto sui generis, permite à sociedade refletir sobre si própria, como uma espécie de consciência. Lobato percebia o caminho de mão dupla que ligava o público à literatura.

O próprio Lobato, numa simples frase, resume sua concepção de literatura (militante mas sem perder de vista a razão mesma de sua existência, a saber, o leitor): U m país se faz com homens e livros.

\section{Referências bibliográficas}

AZEVEDO , Carmen L., CAM ARGO S, M., SACCHETTA, V. M onteiro Lobato - furacão na Botocúndia. São Paulo: SEN AC, 1997.

BOURDIEU, P. As regras da arte. São Paulo: Cia. das Letras, 1996.

BOURDIEU, P. A economia das trocas simbólicas. São Paulo: Perspectiva, 1998. 
Sociologias, Porto Alegre, ano 4, № 7, jan/jun 2002, p. 245-270

CÂNDID O, Antônio. Literatura e sociedade. São Paulo: Cia. Editora Nacional, 1976.

CARNEIRO, Maria L. T. Livros proibidos, idéias malditas - o Deops e as minorias silenciadas. São Paulo: Estação Liberdade, 1997.

DARNTO N, R. O beijo de Lamourette. São Paulo: Cia. das Letras, 1995.

GRISW O LD, Wendy. Recent moves in the sociology of literature. In: Annual review of sociology, 19, 1993, p.455-67.

HALLEW ELL, Laurence. 0 livro no Brasil. São Paulo: EDUSP/T. A. Q ueiroz, especialmente o capítulo XIII, 1985.

KO SHIYAM A, Alice M. M onteiro Lobato - intelectual, empresário, editor. São Paulo: T. A. Q ueiroz, 1982.

LAJO LO, M arisa. A modernidade em M onteiro Lobato. In: ZILBERM AN, R. (O rg.) Atualidade de Monteiro Lobato: uma revisão crítica. Porto Alegre: M ercado Aberto, 1983.

LANDERS, Vasda B. De Jeca a M acunaíma - M onteiro Lobato e o modernismo. Rio de Janeiro: Civilização Brasileira, 1988.

LEITE, Lígia C. M. Sobre João Simões Lopes N eto. In: Sobre o pré-modernismo. Rio de Janeiro: Fundação Casa de Rui Barbosa, 1988.

LEITE, Sylvia H. T. de Almeida. 0 pré-modernismo em São Paulo. In: Revista de Letras. São Paulo/UNESP, v.35, 1995.

LO BATO, M. Idéias de Jeca Tatu. São Paulo: Brasiliense, 1948.

LO BATO, M. A barca de Gleyre. São Paulo: Brasiliense, $1^{\circ}$ tomo, 1951.

LOBATO, M. A barca de Gleyre. São Paulo: Brasiliense, $2^{\circ}$ tomo, 1955.

LOBATO, M. N egrinha. São Paulo: Brasiliense, 1959.

LOBATO, M. Cidades mortas São Paulo: Brasiliense, 1995.

LO BATO, M. U rupês. São Paulo: Brasiliense, 1997. 
MACHADO NETO, A. L. Estrutura social da república das letras. São Paulo: Edusp/ Grijalbo, 1973.

MARTINS, Milena R. E era à máquina e de pijamas que Lobato escrevia. In: LO PES, Eliane M. T. \& GO U VÊA, M aria C. S. Lendo e escrevendo Lobato. Belo Horizonte: Autêntica, 1999.

MICELI, Sérgio. Poder, sexo e letras na República Velha. São Paulo: Perspectiva, 1977.

M O RAES, Pedro R. B. de. Monteiro Lobato e a constituição das editorasnacionais. In: REIS, Elisa; ALM EIDA, M aria H. Tavares de; FRY, Peter (O rgs.). Política e cultura - visões do passado e perspectivas contemporâneas São Paulo: H ucitec/AN PO CS, 1996.

PO NTES, H eloísa. Retratos do Brasil: editores, editoras e 'Coleção Brasiliana' nas décadas de 30,40 e 50. In: MICELI, Sérgio (O rg.). História da ciências sociais no Brasil - Volume 1. São Paulo: Vértice/ID ESP, 1989.

PRADO , Antonio A. Lima Barreto - o crítico e a crise. São Paulo: M artins Fontes, 1989.

SEVCENKO, Nicolau. Literatura como missão. São Paulo: Brasiliense, 1995. 


\section{Resumo}

Baseado no estudo do projeto criador de Monteiro Lobato discuto sua importância, como escritor e editor, para a constituição do campo literário nacional. 0 projeto literário lobatiano implicou na renovação da escrita literária (no que diz respeito aos temas abordados e à utilização das técnicas de linguagem) e na modificação das bases da produção e da distribuição do livro no país, contribuindo de maneira ímpar, no seu tempo, para a formação de um público leitor no Brasil.

Palavras-chave: Monteiro Lobato, campo literário, projeto literário, público leitor, livro. 